\title{
Effect of calcitonin treatment on osteoclast counts in Paget's disease of bone
}

\author{
C. P. Williams, G. MEACHIM, AND W. H. TAYLOR
}

From the Department of Chemical Pathology, Liverpool Area Health Authority (Teaching), Ashton Street, Liverpool L3 5RT and the Department of Pathology, University of Liverpool, UK

SUMMARY Histological and biochemical changes during calcitonin treatment have been studied in 15 patients with Paget's disease of bone. For each patient, osteoclast counts were made by the same observer on serial needle biopsies of diseased bone from the posterosuperior iliac spine. $\vec{N}$ Serial estimations were also made of the serum alkaline phosphatase and urinary hydroxyproline $\vec{N}$ excretion. A total of 66 biopsies was examined (ranging from two to seven per patient). Osteoclast $\vec{N}$ populations and the biochemical measurements were log normally distributed. During calcitonin treatment there was a statistically significant decrease in:

(1) the total osteoclast count per square millimetre;

(2) the number per square millimetre of osteoclasts in resorption cavities on the trabecular surface

(3) the relative proportion of osteoclasts sited in resorption cavities compared with total osteoclasts;

(4) the serum alkaline phosphatase level;

(5) 24-hour urinary hydroxyproline excretion.

On stopping treatment there was a statistically significant increase in all of these histologica $\infty$ and biochemical values except that the proportion of osteoclasts in resorption cavities remaineje low. The trabecular cement line pattern remained abnormal during and after treatment in aा biopsies examined, and complete suppression of osteoclast activity was not observed. One of the patients developed a Paget's osteosarcoma while on calcitonin therapy.

Paget's disease of bone is associated with numerous large and multinucleated osteoclasts (Rasmussen and Bordier, 1974), in which several cytological anomalies, particularly nuclear inclusions, have been described (Rebel et al., 1976). Inhibition of bone resorption, both in vivo and in vitro, by calcitonin (reviewed by Hirsch and Munson, 1969; Göthlin and Ericsson, 1976; Holtrop and King, 1977) has encouraged many workers over recent years to examine the effects of calcitonin in Paget's disease. Despite the now considerable literature on the clinical and biochemical effects of calcitonin in Paget's disease, studies of the histological effects, in particular changes in osteoclast counts, have been relatively sporadic (Woodhouse et al., 1971; Shai et al., 1971). Martin et al. (1977) did not find a statistically significant lowering of osteoclast counts in 19 patients with Paget's disease, in whom bone biopsies were obtained both before and after approximately six months' treatment with porcine

Received for publication 2 May 1978 calcitonin, although the osteoclast counts did fall Eisinger and Laponche (1976) reported, in a semiquantitative histological study of six patients receiving salmon calcitonin, $a$ fall in the total osteoclast counts and a reduction in the bone resorption surfaces. A fall in osteoclast counts would be compatible with, but not a prerequisite for, the biochemical response to calcitonin in Paget's disease if, as is generally believed, the lowered urinary hydroxyproline excretion induced by calcitonin indicates decreased bone collagen turnover.

\section{Material and methods}

Patients were investigated in the metabolic ward of the Liverpool Royal Infirmary. They had no radiological or biochemical evidence of bone disease other than Paget's disease except for osteoarthritis or vertebral demineralisation in a few in stances. Serum calcium, 5-nucleotidase (EC 3.1.3.5) and phosphate excretion indices (Nordin an 
Smith, 1965) were normal. Creatinine clearance averaged $90 \mathrm{ml} / \mathrm{min}$ (lowest value $57 \mathrm{ml} / \mathrm{min}$ ), and 24-hour urinary calcium excretion exceeded $3 \mathrm{mmol}$.

Thirteen patients received 4 MRC units salmon calcitonin (Sandoz Products Ltd, Feltham, Middlesex, UK) subcutaneously on six out of seven days during the initial period of treatment, reducing to a minimum dose thereafter of $100 \mathrm{MRC}$ units three times per week. Two patients received 106 MRC units ( $\frac{2}{3}$ vial) of porcine calcitonin (Calcitare, Armour Pharmaceutical Company, Eastbourne, Sussex, UK) intramuscularly daily. Patients received treatment for an average of nine months (range 4-26 months). They were 60 to 76 years of age on starting treatment. None had previously been given fluoride or glucagon therapy. Before each bone biopsy serum alkaline phosphatase (EC 3.1.3.1) was measured according to the recommendations of the Committee on Enzymes of the Scandinavian Society for Clinical Chemistry and Clinical Physiology (1974). Total 24-hour urinary hydroxyproline excretion (OH-Pr) was measured by a modification of the method of Grant (1964), in which the delay coil was removed and sensitivity was increased by incubating at a higher temperature of $75^{\circ} \mathrm{C}$ with curve regeneration (MSE/Fisons, Crawley, Sussex, UK) of the final peaks.

\section{NEEDLE BIOPSIES}

Two cores of bone, of $7.5 \mathrm{~mm}$ mean length by $2 \mathrm{~mm}$ diameter, were taken within a $1 \mathrm{~cm}^{2}$ area from the same posterior superior iliac spine at each biopsy using a Gardner needle (A 461 LNR-type needle, 13 G, Becton and Dickinson, Wembley, Middlesex, UK). The biopsy site showed radiological and histological changes of Paget's disease in each of the patients. All the biopsies were taken by the same person. A precalcitonin bone biopsy was obtained in 14 out of 15 patients. While the 15 patients were receiving calcitonin, 37 bone biopsies were obtained. Fifteen biopsies were taken from 12 of the patients after they had stopped calcitonin. The first biopsy on calcitonin was taken on average $5 \frac{1}{2}$ months (range 2-13 months) after starting treatment with calcitonin; the first post-calcitonin biopsy was at 7 months (range 2-13 months) after stopping treatment. The biopsies were taken with the informed consent of the patient.

\section{HISTOLOGICAL TECHNIQUES}

The needle plugs were fixed in buffered formol saline immediately after collection, decalcified for eight days in ethylene diamine tetra-acetate (EDTA), and processed by routine methods to give a ribbon of paraffin sections, 7 microns thick, mounted on a separate slide for each plug. The sections were assessed for evidence of increased osteoclastic and osteoblastic remodelling activity, marrow fibrosis, and disturbance of trabecular cement line pattern. Serial determinations of the osteoid content of the biopsies were not included in the present study.

\section{OSTEOCLAST COUNTS}

All the osteoclast counts were performed by the same observer, using a counting zone of $1 \mathrm{~mm}^{2}$ in area moved systematically along the whole of the cancellous bone in the section from contiguous (adjacent) zone to zone. An average of four sections, evenly distributed along the ribbon, were counted from each of the two needle plugs. The total osteoclast count was expressed as the mean number per square millimetre of all the multinucleate osteoclasts identified. Of the multinucleate osteoclasts identified, the 'active' osteoclast count was taken as the mean number per square millimetre of osteoclasts sited in resorption cavities (Howship's lacunae) on the trabecular surface. The remaining osteoclasts were those lying free in the intertrabecular (that is, marrow) spaces. Care was taken to distinguish between osteoclasts and megakaryocytes. The latter, although also multinucleate, were among haemopoietic tissue.

$$
\text { From these results the 'active' index was calculated }
$$

from the formula

$$
\frac{\text { 'active' osteoclast count per } \mathrm{mm}^{2}}{\text { total osteoclast count per } \mathrm{mm}^{2}} \text {. }
$$

\section{Results}

From plots of our data on probability paper (Hoffmann, 1963) the total and active osteoclast populations, and the levels of serum alkaline phosphatase and 24-hour urinary $\mathrm{OH}-\mathrm{Pr}$ excretion, in patients with Paget's disease were found to be log-normally distributed before, during, and after calcitonin treatment. Tests of correlation, paired $t$ and unpaired $t$ tests, were therefore performed using logarithmic values.

In the Table the individual total and 'active' osteoclast counts before, during, and after treatment with calcitonin have been set out, together with the patient's age and sex.

In Fig. 1, total and 'active' osteoclast counts from different periods after starting and after finishing calcitonin treatment have been expressed as mean percentages of the corresponding precalcitonin total and 'active' osteoclast counts. 
Table Total and ('active') osteoclast counts from patients with Paget's disease before, during, and after calcitonin treatment

\begin{tabular}{|c|c|c|c|c|c|c|c|c|}
\hline \multirow[t]{2}{*}{ Patient } & \multirow[t]{2}{*}{ Sex } & \multirow[t]{2}{*}{ Age } & \multicolumn{6}{|c|}{ Total and ('active') osteoclast counts } \\
\hline & & & Precalcitonin & \multicolumn{3}{|l|}{ On calcitonin } & \multicolumn{2}{|l|}{ Post calcitonin } \\
\hline 1 & $\mathbf{F}$ & 65 & $3 \cdot 0(2 \cdot 0)$ & & $\begin{array}{l}1.5(1.0) \dagger \\
0.6(0.3)\end{array}$ & $0.8(0.3)$ & & $4 \cdot 8(2 \cdot 2)$ \\
\hline 2 & $\mathbf{M}$ & 76 & $4 \cdot 5(3 \cdot 0)$ & $4 \cdot 5(1 \cdot 5)$ & $1 \cdot 0(0 \cdot 2)$ & \multicolumn{2}{|c|}{ Died with an osteosarcoma } & \\
\hline 4 & $\mathbf{M}$ & 62 & $3.0(1 \cdot 5)$ & $1.6(1.0)$ & & $1.4(0.6)$ & $3 \cdot 8(1 \cdot 2)$ & $3.8(1.9)$ \\
\hline $5 *$ & $\mathbf{F}$ & 75 & $12.0(5 \cdot 0)$ & & $2 \cdot 5(1 \cdot 5)$ & Died in conges & ve cardiac failure & \\
\hline 6 & $\mathbf{M}$ & 71 & $1.0(0.7)$ & $1.0(0.5)$ & & $1 \cdot 2(0 \cdot 7)$ & $2 \cdot 2(1 \cdot 0)$ & \\
\hline 7 & $\mathbf{F}$ & 73 & $3.0(1 \cdot 5)$ & $2 \cdot 7(1 \cdot 5)$ & $2 \cdot 6(1 \cdot 0)$ & $\begin{array}{l}2.2(1.0) \\
2.6(0.9)\end{array}$ & No biopsy & \\
\hline 8 & $\mathbf{M}$ & 65 & $3 \cdot 5(1 \cdot 5)$ & $1 \cdot 7(0 \cdot 8)$ & & & & $4.0(1.8)$ \\
\hline 9 & $\mathbf{M}$ & 73 & $2 \cdot 1(1 \cdot 3)$ & $2 \cdot 1(1 \cdot 2)$ & $1 \cdot 4(0 \cdot 6)$ & & $\begin{array}{l}3.9(1.6) \\
2.0(1 \cdot 1)\end{array}$ & \\
\hline 10 & $\mathbf{M}$ & 69 & $1.0(0.4)$ & & $\begin{array}{l}0.4(0.2) \\
0.5(0.3)\end{array}$ & $\begin{array}{l}0.5(0.3) \\
0.3(0.1)\end{array}$ & & $1 \cdot 1(0 \cdot 3)$ \\
\hline 11 & $\mathbf{F}$ & 69 & $3.0(1 \cdot 0)$ & & $\begin{array}{l}3.0(1.0) \\
3.5(1.6)\end{array}$ & $\begin{array}{l}2.0(0 \cdot 8) \\
5 \cdot 2(2 \cdot 0)\end{array}$ & & $\begin{array}{l}2 \cdot 2(1 \cdot 0) \\
3 \cdot 1(1 \cdot 2)\end{array}$ \\
\hline $\begin{array}{l}12 \\
13\end{array}$ & $\begin{array}{l}\mathbf{M} \\
\mathbf{M}\end{array}$ & $\begin{array}{l}64 \\
53\end{array}$ & $\begin{array}{l}3.0(1 \cdot 8) \\
2.2(1 \cdot 2)\end{array}$ & $0.8(0.2)$ & & $\begin{array}{l}2.2(1.1) \\
1.0(0.4)\end{array}$ & $\begin{array}{l}3.2(1.4) \\
1.9(0.8)\end{array}$ & \\
\hline $14^{*}$ & $\mathbf{M}$ & 69 & No biopsy & & $1.0(0.5)$ & $\begin{array}{l}1.5(1.0) \\
1.7(0.4)\end{array}$ & & $2 \cdot 1(1 \cdot 0)$ \\
\hline 15 & $\mathbf{F}$ & 68 & $14 \cdot 0(7 \cdot 0)$ & $4 \cdot 5(1 \cdot 5)$ & $4 \cdot 6(2-0)$ & $5 \cdot 4(2 \cdot 5)$ & & $4 \cdot 1(1 \cdot 7)$ \\
\hline
\end{tabular}

* Patients receiving porcine calcitonin.

†Where two values appear in any column, the upper value was that of the earlier biopsy.

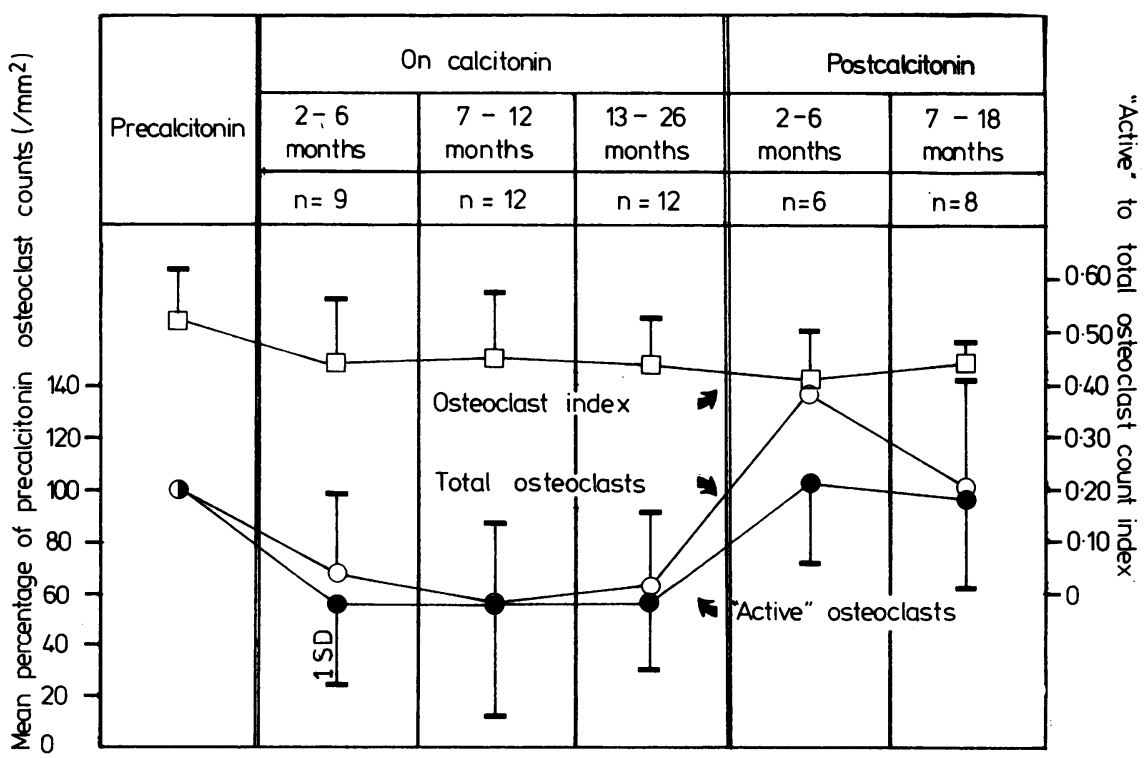

Fig. 1 Total and 'active' osteoclast counts from bone biopsies of patients with Paget's disease of bone before, during, and after treatment with calcitonin. The mean 'active' to total osteoclast count index is also shown. The mean precalcitonin total osteoclast count was 4.2 (SD 3.9) $/ \mathrm{mm}^{2}$ and the mean 'active' osteoclast count was $2 \cdot 1$ (SD 1.8)/ $/ \mathrm{mm}^{2}$. Each bar indicates $1 S D . n=$ number of pairs (precalcitonin, on calcitonin, or post-calcitonin) from which each mean percentage value is derived. 
Mean precalcitonin total osteoclast counts were $4.2 / \mathrm{mm}^{2}$ (SD 3.9) and 'active' osteoclast counts $2 \cdot 1 / \mathrm{mm}^{2}$ (SD 1.8). Mean total and 'active' osteoclast counts decreased significantly $(P<0.01$ and $P<0.02$, respectively) during calcitonin treatment, falling at six months to $68 \%$ and $56 \%$ respectively of the corresponding precalcitonin counts. The fall in osteoclast counts noted within the first six-month period of calcitonin treatment was not significantly greater in the second six-monthly and subsequent periods on calcitonin.

The mean of the individual 'active' indices before calcitonin was 0.53 (SD 0.11 ). In the same patients, this index decreased significantly during treatment to 0.44 (SD 0.11) $(P<0.05)$, implying a proportional as well as an absolute decrease in the osteoclasts in resorption cavities.

Both total and 'active' osteoclast counts increased significantly ( $P$ values $<0.005$ ) after calcitonin was stopped when compared with the mean counts during treatment. However, the mean of the 'active' osteoclast indices remained decreased $(0.43$, SD 0.07) after stopping calcitonin, and was little different from the mean index $(0.45$, SD 0.11$)$ for the same patients while on calcitonin. Furthermore, comparison of 11 of the patients for whom both preand post-calcitonin indices were available showed the mean index to have remained significantly $(\mathbf{P}<0.02)$ lower after calcitonin was stopped
$(0.42$, SD 0.07) compared with the mean precalcitonin index (0.52, SD 0.11).

Mean serum alkaline phosphatase and 24-hour urinary $\mathrm{OH}-\mathrm{Pr}$ excretion also fell significantly ( $P$ values $<0.005)$ during treatment, and increased significantly ( $P$ values $<0.005$ ) post calcitonin, compared with the mean values during treatment.

In Fig. 2, serum alkaline phosphatase and 24-hour urinary OH-Pr excretion, during and after calcitonin treatment, are expressed as percentages of the corresponding precalcitonin values. Mean precalcitonin serum alkaline phosphatase was 2563 (SD 2244) IU/l (normal range 60-330 IU/l) and urinary OH-Pr excretion 1764 (SD 873) mmol/ day (normal range 115-270 mmol/day). The increase in the ratio of serum alkaline phosphatase to urinary $\mathrm{OH}-\mathrm{Pr}$ excretion while on calcitonin, as may be deduced from Fig. 2, confirms the observations of Kanis et al. (1975).

\section{TRABECULAR CEMENT LINE}

In all the biopsies examined histologically before, during, and after calcitonin, the cancellous bone trabeculae showed an abnormality, often of frank 'mosaic' type in places, of their cement-line pattern. The abnormality usually affected from one-half to three-quarters of the total trabecular tissue; at the microscopic level the disturbed osseous seams were often intimately admixed with others in more normal alignment. Calcitonin treatment produced no obvious change in the proportion of trabecular

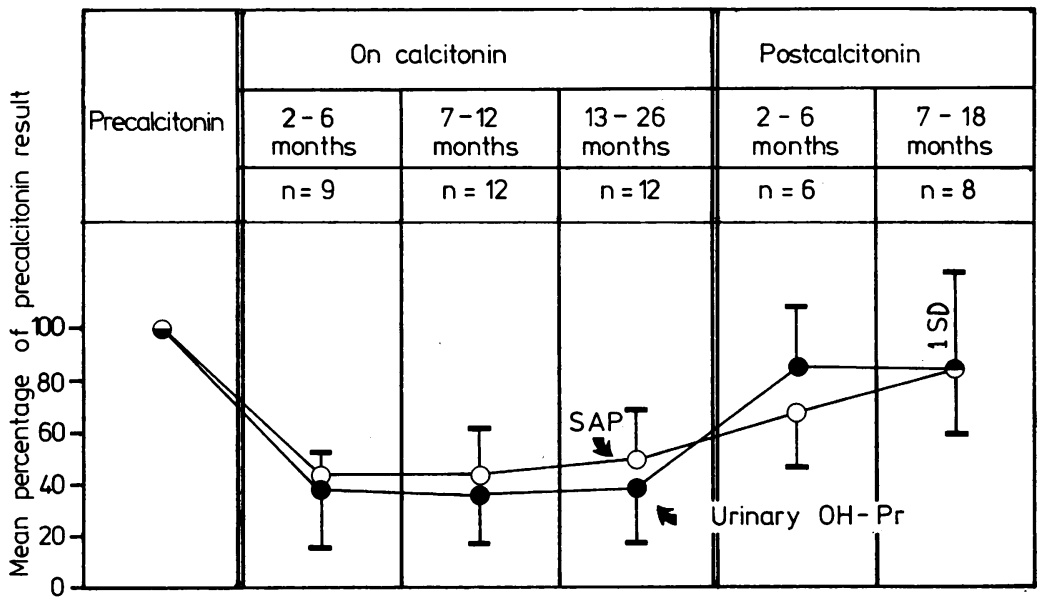

Fig. 2 Serum alkaline phosphatase and 24-hour urinary OH-Pr excretion of patients with Paget's disease of bone before, during, and after treatment with calcitonin. The mean precalcitonin serum alkaline phosphatase was 2562 (SD 2244) IU/l and the mean urinary OH-Pr excretion was 1764 (SD 873) mmol/day. Each bar indicates $1 S D . n=$ number of pairs (precalcitonin, on calcitonin, or postcalcitonin) from which each mean percentage is derived. 
tissue showing cement-line pattern abnormality.

PATIENT MORTALITY

One patient, despite a good clinical and biochemical response to calcitonin, died of an osteosarcoma, which developed in an area of Paget's bone during calcitonin treatment. Another 75-year-old woman with extensive Paget's disease and high-output cardiac failure also died during calcitonin treatment from mitral valve disease.

\section{BIOCHEMICAL AND HISTOLOGICAL}

\section{CORRELATIONS}

Before treatment, serum alkaline phosphatase and $\mathrm{OH}-\mathrm{Pr}$ excretion were significantly linearly correlated with each other $(r=+0.76, P<0.005)$ but neither showed a statistically significant correlation with total or 'active' osteoclast counts. During treatment with calcitonin there was a small $(r=+0.66)$ but significant $(P<0.001)$ correlation between urinary $\mathrm{OH}-\mathrm{Pr}$ excretion and total osteoclast counts. There was no indication of any relationship between serum alkaline phosphatase and total or 'active' osteoclast counts, although serum alkaline phosphatase and $\mathrm{OH}-\mathrm{Pr}$ excretion remained related to each other during calcitonin treatment $(r=+0.54$, $\mathrm{P}<0.005)$ and afterwards $(\mathrm{r}=+0.92, \mathrm{P}<0.001)$.

\section{Discussion}

Clinical and radiological experience indicates that Paget's disease of bone is often asymptomatic and that only a minority of patients with this disease require treatment. For such patients the present study shows that calcitonin, at least in the dosages here used, will dampen the activity of the pathological process. Complete suppression of osteoclast activity, however, was not observed; moreover, the study did not show a change of bone histology to a 'normal' appearance, since the trabecular cement-line pattern remained disturbed during and after treatment in all the biopsies examined.

In Paget's disease the decrease in serum alkaline phosphatase and OH-Pr excretion under the influence of calcitonin has been established from the work of numerous investigators. The data on osteoclasts are sparse and less decisive for a number of reasons. Firstly, although a carefully conducted bone biopsy should be essentially free from pain and complications, there has probably been a reluctance towards bone sampling. Secondly, regional differences in the distribution of osteoclasts must affect the comparative results of osteoclast counts (Martin et al., 1977) and are a source of sampling error. We have tried to reduce this error by taking two bone samples at each biopsy. Also all biopsies were taken by one person, and by careful examination the previous site of skin entry could be identified at subsequent biopsies. Thirdly, osteoclast counting is open to interobserver variation, and to eliminate this source of error all the osteoclast counting has been performed by the same observer.

The present study shows that the dampening effect of calcitonin on the activity of Paget's disease, as measured by serial biochemical estimations, is accompanied by a dampening effect on osteoclasts at the tissue level, as measured by their total number in the Paget's bone, their number in resorption cavities, and the proportion of 'active' to total osteoclasts. The sustained and relatively high doses of calcitonin used should be noted.

Martin et al. (1977) compared osteoclast counts from only two biopsies in each of 15 patients. The second biopsy was taken after five to 17 months of treatment, but the mean fall of $29.1 \%$ from the first pretreatment biopsy was said not to be of statistical significance. As we have found the osteoclast populations of Paget's patients to be log-normally distributed, we have applied a paired $t$ test to the logarithms of Martin's published pre and during calcitonin osteoclast counts. The fall in total osteoclast counts on calcitonin was then significant $(\mathrm{P}<0.01)$. Martin et al. (1977) used only porcine calcitonin, and the initial dosage of 80 MRC units daily was less than in our investigation. Eisinger and Laponche (1976) studied six patients with Paget's disease who received salmon calcitonin-'about thirty injections of an average of 50 MRC units over eight to 14 weeks'. Without offering a statistical analysis, they find a decrease in the number of osteoclasts in the three patients in whom appropriate counts were made.

Our results establish that during treatment with calcitonin the osteoclast count falls to a 'plateau', as has been well described for serum alkaline phosphatase and OH-Pr. As long as treatment is maintained (up to 26 months) the effect persists. When treatment is stopped the total osteoclast count returns to pretreatment levels. From the clinical point-of-view the fall of osteoclasts, serum alkaline phosphatase, and $\mathrm{OH}-\mathrm{Pr}$ indicates that calcitonin treatment could continue indefinitely. However, in practice, treatment is discontinued after three to nine months because of absence of further improvement in bone pain, the inconvenience and expense of the injections, and the development in some patients of a marked hypercalciuria.

Interestingly, in our study, while OH-Pr excretion correlated significantly with total osteoclast counts when the patients were receiving calcitonin, it 
did not do so before or after calcitonin. From an examination of the statistical data it did not appear that this finding was due to the smaller number of pre- and post-calcitonin samples.

The likely explanation is that OH-Pr excretion reflects the extent of the disease, that is, the total number of osteoclasts in the individual patient, whereas the osteoclast count measures the 'concentration' of cells in bone, that is, osteoclasts per square millimetre. A pretreatment correlation between the two would be expected only if the extent of the disease was the same in each patient, which was not the case. When the 'concentration' of cells in each patient fell, under the influence of calcitonin, together with a fall in OH-Pr excretion, an apparent correlation might arise because the range of individual values for both counts and $\mathrm{OH}-\mathrm{Pr}$ excretion would be narrower.

The change in the proportion of 'active' to total osteoclasts is unexplained. Calcitonin acts on the ruffled borders of osteoclasts (Kallio et al., 1972), and it is conceivable that some change in the surface characteristics of osteoclasts affects their activity. There is evidence from tracer study work (reviewed by Göthlin and Ericsson (1976)) that some osteoclasts survive for at least 28 days, in which case the biochemical reactivation after stopping calcitonin in Paget's disease may represent a gradual replacement of a calcitonin-exposed osteoclast population by a more abundant and possibly more active osteoclast population. It would be of interest to examine the ultrastructural features of the calcitonin-exposed osteoclasts in Paget's disease.

We thank Sandoz Products Ltd, Middlesex, UK for the generous gift of the salmon calcitonin used in treating our patients.

\section{References}

Eisinger, J., and Laponche, A. M. (1976). Traitement discontinu de la maladie de Paget par la calcitonine: étude histolgique. Revue du Rhumatisme et des Maladies Osteo-articulaires, 43, 511-516.

Göthlin, G., and Ericsson, J. L. E. (1976). The osteoclast. Clinical Orthopaedics and Related Research, 120,
201-231.

Grant, R. A. (1964). Estimation of hydroxyproline by the autoanalyser. Journal of Clinical Pathology, 17, 685-689.

Hirsch, P. F., and Munson, P. L. (1969). Thyrocalcitonin. Physiological Reviews, 49, 548-622.

Hoffmann, R. G. (1963). Statistics in the practice of medicine. Journal of the American Medical Association, 185, 864-873.

Holtrop, M. E., and King, G. J. (1977). The ultrastructure of the osteoclast and its functional implications. Clinical Orthopaedics and Related Research, 123, 177-196.

Kallio, D. M., Garant, P. R., and Minkin, C. (1972.) Ultrastructural effects of calcitonin on osteoclasts in tissue culture. Journal of Ultrastructural Research, 39, 205-216.

Kanis, J. A., Fitzpatrick, K., and Strong, J. A. (1975). Treatment of Paget's disease of bone with porcine calcitonin: clinical and metabolic responses. Quarterly Journal of Medicine, 44, 399-413.

Martin, T. J., Jerums, G., Melick, R. A., Zipell, J. M., and Arnott, R. (1977). Clinical, biochemical and histological observations on the effect of porcine calcitonin in Paget's disease of bone. Australian and New Zealand Journal of Medicine, 7, 36-43.

Nordin, B. E. C., and Smith, D. A. (1965). Diagnostic Procedures in Disorders of Calcium Metabolism, p. 268. Churchill, London.

Rasmussen, H., and Bordier, P. (1974). The Physiological and Cellular Basis of Metabolic Bone Disease. Williams and Wilkins, Baltimore.

Rebel, A., Malkani, K., Baslé, M., and Bregeon, C. (1976). Osteoclast ultrastructure in Paget's disease. Calcified Tissue Research, 20, 187-199.

Scandinavian Society for Clinical Chemistry and Clinical Physiology, Committee on Enzymes (1974). Recommended methods for the determination of four enzymes in blood. Scandinavian Journal of Clinical and Laboratory Investigation, 33, 291-306.

Shai, F., Baker, R. K., and Wallach, S. (1971). The clinical and metabolic effects of porcine calcitonin on Paget's disease of bone. Journal of Clinical Investigation, 50, 1927-1940.

Woodhouse, N. J. Y., Bordier, P., Fisher, M., Joplin, G. F., Reiner, M., Kalu, D. N., Foster, G. V., and MacIntyre, I. (1971). Human calcitonin in the treatment of Paget's bone disease. Lancet, 1, 1139-1143.

Requests for reprints to: Dr C. P. Williams, Department of Chemical Pathology, Liverpool Area Health Authority (Teaching), Ashton Street, Liverpool L3 5RT, UK. 